\title{
FÓRUM
}

Recebido em 15.02.2013. Aprovado em 04.06.2013.

Avaliado pelo sistema double blind review. Editores Científicos: Edgard Barki, Delane Botelho e Juracy Parente

DOI: http://dx.doi.org/10.1590/S0034-75902013005000004

\section{PERSONALIDADE E BOCA A BOCA: PROPENSÃO AO ENVIO E RECEBIMENTO DE INFORMAÇÕES}

\author{
Personality and word-of-mouth: propensity of sending and receiving information \\ Personalidad y boca a boca: propensión al envío y recibo de informaciones
}

\begin{abstract}
RESUMO
Este artigo propõe-se a avaliar a ligação entre traços de personalidade e a disposição para o boca a boca. Por meio da modelagem de equações estruturais, verificou-se que o envio de informações foi significativamente antecedido pela amabilidade, instabilidade emocional e consciência. 0 recebimento de informações foi significantemente precedido pela instabilidade emocional e pela consciência. No âmbito acadêmico, este estudo contribui para a compreensão das ligações entre a personalidade e o envio e recebimento de informações pelo consumidor, testando empiricamente um modelo que faz essa junção entre construtos psicológicos com construtos trabalhados em marketing. Gerencialmente, este estudo contribui para a compreensão do comportamento do consumidor e fornece indícios para a tomada de decisão quando a intenção é prevenir o boca a boca negativo ou instigar o boca a boca positivo.
\end{abstract}

PALAVRAS-CHAVE | Comportamento do consumidor, personalidade, boca a boca, envio de informações, recebimento de informações.

\begin{abstract}
This article aims to assess the connection between personality traits and willingness to word of mouth. By means of structural equation modeling, it was found that the sending of information was significantly preceded by a miability, emotional instability, and consciousness. The receiving of information was significantly preceded by emotional instability and consciousness. In the academic context, this study contributes to the understanding of connections between personality and sending and receiving of information by consumers, by empirically testing a model that makes the junction between psychological constructs with marketing constructs. At the managerial level, this study contributes to the understanding of consumer behavior and provides evidence for decision making when the intention is to prevent negative word of mouth or to instigate positive word of mouth.
\end{abstract}

KEYWORDS / Consumer behavior, personality, word of mouth, sending of information, receiving of information.

Professor da Escola de

Administração da Faculdade

Meridional - Passo Fundo - RS,

Brasil

\section{DANÚBIA RECK}

danubiareck@yahoo.com.br Pós-graduanda na Faculdade Meridional - Passo Fundo-RS, Brasil

\section{EDUARDO RECH}

ddrech@gmail.com

Professor da Escola de

Administração da Faculdade Meridional - Passo Fundo - RS, Brasil

\section{RESUMEN}

Este artículo se propone evaluar la relación entre trazos de la personalidad y la disposición para la discusión. Pormedio del modelaje de ecuaciones estructurales, se verificó que el envío de informaciones fue significativamente antecedido por la amabilidad, inestabilidad emocional y la consciencia. La recepción de informaciones fue significantemente precedida por la inestabilidad emocional y por la consciencia. En el ámbito académico, este estudio contribuyó para la comprensión de las relaciones entre la personalidad y el envío y la recepción de informaciones por parte del consumidor, probando empíricamente un modelo que hace esa relación entre construcciones psicológicas con construcciones trabajadas en marketing. Fundamentalmente, este estudio contribuye para la comprensión del comportamiento del consumidor y provee indicios para la toma de decisión cuando surge la intención y prevenir la discusión negativa e instigar la discusión positiva.

PALABRAS CLAVE / Comportamiento del consumidor, personalidad, discusión, envío de informaciones, recepción de informaciones. 


\section{INTRODUÇÃO}

Existem diversas formas de as empresas divulgarem suas marcas e produtos, mas, apesar de os gestores utilizarem meios cada vez mais criativos para atrair os clientes, o boca a boca continua tendo forte influência nas decisões e escolhas dos consumidores. Segundo pesquisa realizada pela Nielsen (2012), $92 \%$ dos consumidores mundiais dizem confiar mais em informações proveniente de fontes conhecidas, como o boca a boca e a opinião de amigos e familiares, do que em outros meios (p. ex., propagandas). Nesse sentido, o boca a boca deve ser um fator observado pelos varejistas, pois esse tipo de comunicação pode ajudar ou prejudicar as vendas. De acordo com dados do McKinsey Quarterly (2010), o boca a boca é o fator mais considerado nas decisões de compra, influenciando cerca de $50 \%$ de todas as decisões do consumidor. Saber como usar esse meio de comunicação pode trazer grandes recompensas para os varejistas; apesar de muitos comerciantes negligenciarem o boca a boca, essa comunicação pode ocasionar mais vantagem competitiva do que qualquer outra abordagem de marketing (MCKINSEY QUARTERLY, 2010).

Conhecer o consumidor, seus comportamentos e seu processo decisório tem sido um dos principais desafios do marketing nos últimos tempos. Entre esses comportamentos, o boca a boca exerce grande importância no relacionamento entre empresa e consumidor. Aliado a isso, a comunicação boca a boca é um processo de influência interpessoal que pode ser significativo para as decisões e estratégias de marketing em uma organização, pois tem sua relevância no processo de tomada de decisão de compra do consumidor. Duan, Gu e Whinston (2008) afirmam que o boca a boca desempenha, cada vez mais, um papel fundamental nas escolhas dos consumidores. Eles podem ser afetados pelas informações do boca a boca por meio de comunicação pessoal ou on-line, e essas informações podem ajudá-los a estruturar sua decisão de compra ou sua percepção sobre a marca (ZHU e ZHANG, 2010). Segundo Duan, Gu e Whinston (2008), com o avanço dos meios de comunicação on-line, o boca a boca apresenta muitos desafios e oportunidades para os varejistas. O boca a boca, estrategicamente, para as empresas, também é importante porque estudos comprovam a sua ligação com variáveis pós-compra, relacionadas com a performance organizacional, como a satisfação e a lealdade (CHEUNG, ANITSAL, ANITSAL, 2007).

Além de as semelhanças entre emissor e receptor serem relevantes para o processo de boca a boca, sabe-se que processos motivacionais internos podem representar uma disposição significativa para o início desse processo (CHEUNG, ANITSAL, ANITSAL, 2007). Por isso, a personalidade, por representar as reais disposições internas do indivíduo e os seus processos motivacionais (MOWEN, 2000), pode estar ligada à expressão dos comportamentos de boca a boca. Dessa forma, compreender como a personalidade do sujeito está ligada à disposição de enviar e receber informações ao mercado representa um avanço importante na compreensão do comportamento de boca a boca dos consumidores.

Assim, este artigo propõe-se a avaliar a ligação entre traços de personalidade e a disposição para o boca a boca. Desse modo, espera-se suscitar a importância do relacionamento de construtos psicológicos com construtos tradicionalmente trabalhados em comportamento do consumidor. Especificamente, espera-se contribuir com o entendimento sobre os processos de envio e recebimento de informações do mercado, como disposições relacionadas ao boca a boca. Gerencialmente, espera-se que este artigo traga uma possibilidade de ação para os gestores instigarem o envio de informações, por meio de comunicações específicas, e compreenderem quais traços de personalidade deixam as pessoas mais suscetíveis ao recebimento de informações.

\section{PERSONALIDADE E TEORIA DOS TRAÇOS}

Considera-se que a personalidade é resultado da influência de diferentes fatores sobre o indivíduo. Segundo Gazzaniga e Heatherton (2005, p. 471), “a personalidade se refere às características, respostas emocionais, pensamentos e comportamentos que são relativamente estáveis ao longo do tempo em diferentes circunstâncias". A personalidade contém em seu escopo a ideia de que cada indivíduo possui a sua organização de personalidade. Ao analisar diversos indivíduos, no entanto, nota-se que determinados padrões emergem de características semelhantes. A teoria dos traços de personalidade representa uma linha de pesquisa dentro da personalidade, a qual encontra, na distinção entre os indivíduos, formas de provocar a busca por padrões.

0 marketing tem sido guiado pela corrente dos traços, que, de acordo com Mowen (2000), procura estudar as dimensões básicas da personalidade. Traço de personalidade, que, de acordo com Gazzaniga e Heatherton (2005, p. 471), “é uma característica; uma tendência disposicional a agir de certa maneira ao longo do tempo e em diferentes circunstâncias", pode ser representado, conforme Weiten (2006), por adjetivos como honesto, digno de confiança, temperamental, impulsivo, desconfiado, ansioso, excitável, dominador e amigável. De acordo com McCrae e Costa (1997), a estrutura de traços que compõem a personalidade é formada por um pequeno número de 
fatores que se correlacionam para representar as dimensões mais básicas da personalidade.

De acordo com Goldberg (1993), seguindo a teoria dos traços, Warren Norman formulou a teoria Big Five, baseada em um modelo de cinco grandes fatores de personalidade. McCrae e Costa (1987) verificaram que esses cinco fatores são capazes de distinguir as personalidades de dois indivíduos, categorizando-as. Os cinco fatores são: neurotismo, relativo ao grau de instabilidade emocional, isto é, revela a tendência para emotividade expressa pelo mau humor e indícios de atividade temperamental; introversão mostra o quanto uma pessoa não se engaja e distancia-se da companhia de outras, bem como é a tendência a revelar sentimentos de timidez e desconfiança; amabilidade é o cuidado para não ser hostil ou faltar com respeito, sentindo necessidade de expressar bondade e simpatia com os outros; consciência é a necessidade de ser organizado, ordenado e eficiente nas tarefas; e abertura à experiência, ou seja, o quanto um indivíduo está disposto a aceitar novas ideias, encontrar soluções novas, expressar ideias originais e usar a imaginação no desenvolvimento de tarefas. Em seu estudo, McCrae e Costa (1997) mostraram que a estrutura dos cinco fatores pode ser universal. Nesse sentido, Schmitt e outros (2008) também verificaram a presença dos cinco fatores em 55 diferentes nações, permitindo a análise da universalidade dos fatores do Big Five.

Na área de marketing, Hurley (1998) analisou o efeito dos cinco fatores na performance de vendas de colaboradores de fronteira de organizações de serviço. Em outro estudo, Janssens e Pelsmacker (2009) relacionaram os cinco fatores de personalidade com as escolhas de perfume e predileções por aromas dos consumidores. Mulyanegara, Tsarenko e Anderson (2009), por sua vez, encontraram relações entre dimensões de marca e traços de personalidade dos consumidores, evidenciando, por exemplo, que indivíduos com altos níveis do traço de consciência demonstram preferência por marcas confiáveis, enquanto indivíduos extrovertidos preferem marcas com caráter "sociável".

\section{Personalidade e comportamento do consumidor}

Muitos fatores afetam o comportamento humano e, especificamente, o processo de tomada de decisão, pois as constituições individuais fazem com que os enfoques e os resultados sejam diferentes para cada indivíduo (JAAKKOLA, 2007). No estágio pós-compra, dentro do processo de decisão de compra do consumidor, verifica-se que, na maioria dos modelos, a personalidade tem sido proposta como um importante antecedente (SINGH, 1990).
Mowen, Park e Zablah (2007, p. 590) mencionam que “o estudo do impacto da personalidade sobre o comportamento do consumidor é atrasado devido à lacuna de estruturação teórica sem a presença de uma rede nomológica de traços preditores". Sob o intuito de verificar a relação entre a personalidade e o comportamento do consumidor, Horton (1979) evidenciou que os traços de ansiedade geral e orientação para a tarefa aproximaram-se mais para influenciar o comportamento do consumidor e, ainda, que os consumidores com altos níveis do traço de orientação à tarefa são mais propensos a demonstrar uma comparação baseada em fatos de marcas concorrentes.

Não obstante, diversos estudos foram realizados procurando encontrar relações entre a personalidade e outros construtos de comportamento do consumidor. Harris e Mowen (2001) utilizaram o Modelo 3M (Modelo Metateórico de Motivação e Personalidade) procurando relações entre a personalidade e as intenções de barganha e reclamação, enquanto Mowen e Carlson (2003) fizeram uso do mesmo modelo procurando explicações para o comportamento de superstição. Bodey e Grace (2006) utilizaram-se da personalidade para prover meIhores bases para segmentação de clientes, entre reclamantes e não reclamantes. Monteiro e Veiga (2006) aplicaram o Modelo 3M de Mowen (2000) com o intuito de prever hábitos de compra de artigos esportivos e de moda. Além de Monteiro e Veiga (2006), no Brasil, outros estudos também estudaram recentemente a ligação entre a personalidade e o comportamento dos consumidores (PIESKE e PRADO, 2012; MONTEIRO, VEIGA, GONÇALVES, 2009; MONTEIRO e VEIGA, 2009).

No esforço de entender o comportamento do consumidor, Mittal (1994) apresentou uma gama de variáveis para capturar a forma de uso de produtos, encontrando que a lealdade possui ligações com traços psicológicos de compra. Bodey e Grace (2006) afirmam que os traços de personalidade podem, em alguns casos, ao invés de instigar o comportamento, reprimi-lo, fazendo com que os indivíduos não exprimam suas verdadeiras intenções, passando a agir de acordo com "pseudofiltros" ativados pelos traços de personalidade. Mooradian e Olver (1997) consideram a personalidade passível de utilização para o estudo de predição de processos de pós-compra. Estudando mais especificamente a lealdade, Bove e Mitzifiris (2007) encontraram evidências que podem ligar a predisposição à lealdade a traços de personalidade.

Por fim, não é de admirar que não haja muitos estudos contemporâneos sobre a relação entre personalidade e consumo, devido à grande resistência aos resultados e tentativas falhas, no entanto é clara a importância da personalidade e das pesquisas nesse campo, para que haja uma congruência da área e uma futura consolidação dos diversos fragmentos existentes (BAUMGARTNER, 2002; MOWEN, 2000). 


\section{BOCA A BOCA}

Em seu artigo, Mazzarol, Sweeney e Soutar (2007) citam que o boca a boca pode ser resultado das avaliações da qualidade de um serviço e da percepção de valor formada pelo consumidor após a interação com o prestador do serviço ou produto. Matos e Rossi (2008) consideram o boca a boca dentro do grande conjunto de influências interpessoais no comportamento do consumidor. Esse construto tem sido estudado no contexto de gestão de marketing e comportamento de consumo (p. ex., RANAWEERA e PRABHU, 2003), e também é tratado como parte do conceito maior de lealdade (ZEITHAML, BERRY, PARASURAMAN, 1996). Para Mazzarol, Sweeney e Soutar (2007), porém, o boca a boca não é uma faceta da lealdade e, sim, um construto distinto.

Mazzarol, Sweeney e Soutar (2007) afirmam que o boca a boca influencia as percepções do indivíduo sobre os serviços e produtos, fazendo com que ocorram mudanças nos julgamentos, níveis de avaliação e probabilidades de compra. Esse tipo de comunicação, de acordo com os autores, também auxilia na redução das incertezas pós-compra e na redução de risco na avaliação das alternativas em processo de tomada de decisão de compra, ao passo que se constitui em uma fonte de informações. Em outras palavras, o boca a boca influencia a confiança, que, por sua vez, está presente nos canais de marketing, ao passo que o indivíduo tende a só indicar um produto ou serviço para um amigo se realmente acredita nesse produto ou serviço, transmitindo, desse modo, a confiança baseada na indicação.

Libai e outros (2010) mencionam que há lacunas no estudo da comunicação boca a boca, como a ligação desse comportamento com disposições internas do indivíduo. Embora vários trabalhos abordem os antecedentes do boca a boca como um todo (ver MATOS e ROSSI, 2008, para uma meta-análise), poucos estudos relacionam a personalidade com esse construto (p. ex., MOORADIAN e SWAN, 2006; MOORADIAN e OLVER, 1997). Além disso, a maioria dos estudos que abordam o boca a boca (p. ex., RANAWEERA e PRABHU, 2003) o faz tratando esse construto como unidimensional, ou seja, como a expressão de um comportamento de envio de informações ao mercado. Conforme mencionam e analisam Mowen, Park e Zablah (2007), todavia, os indivíduos possuem disposições internas (traços de personalidade) que tornam a expressão do comportamento de boca a boca mais provável de ocorrer; nesse sentido, pode-se conceber que os indivíduos possuem disposições tanto para o envio quanto para o recebimento de informações, atividades consideradas dentro do escopo do boca a boca por Mowen, Park e Zablah (2007).

Diante disso, este estudo, ao dividir as disposições de boca a boca em envio e recebimento de informação, procura relacioná-las com características mais elementares dos indivíduos, ou seja, os seus traços de personalidade.

\section{Boca a boca e personalidade}

De acordo com Bansal e Voyer (2000), o boca a boca pode ser influenciado por forças interpessoais e não interpessoais, ou seja, forças que residem nas relações entre os indivíduos ou forças externas a essas relações. Como forças interpessoais, Bansal e Voyer (2000) citam a procura ativa por informação e sua retenção, em que há o emissor e o receptor da mensagem, e a presença de disposições cognitivas tanto de um quanto de outro para a troca de informações sobre um determinado bem ou serviço; e a força do engajamento em uma comunicação, que, por sua vez, é a força que trabalha para unir os participantes da comunicação por meio da proximidade, intimidade, suporte e associação entre a comunicação e os indivíduos dela participantes.

Cheung, Anitsal e Anitsal (2007) afirmam que o boca a boca pode ter início em um consumidor que se encontra satisfeito com um produto ou com uma experiência de serviço, porém apenas a satisfação não conduz esse consumidor a engajar-se em um processo de boca a boca. Para que isso ocorra, os autores afirmam que é necessário esse consumidor estar motivado para tal. As motivações encontradas no estudo feito por Cheung, Anitsal e Anitsal (2007) foram: procura por retaliação; procura por compensação; procura por poder de barganha; e altruísmo, especialmente quando analisada a ligação entre as pessoas. 0 altruísmo, como uma motivação para o boca a boca, pode representar um conceito semelhante ao de amabilidade, procurando intervir nas relações sociais de um grupo.

No mesmo sentido, quanto aos antecedentes do boca a boca, Kempf e Palan (2006) citam que o grau de semelhança entre o comunicador e o receptor da mensagem atua como um significativo predecessor. Essas semelhanças podem ser relativas a preferências ou características pessoais, como a personalidade. Alguns estudos mostram que a comunicação boca a boca é mais consistente quando o comunicador é percebido pelo receptor como semelhante, o que conduz a uma maior credibilidade e confiança nas informações (BEARDEN, NETEMEYER, TEEL, 1989; PRICE, FEICK, HIGIE, 1989).

Mooradian e Swan (2006), por meio de uma amostra de 11 países, com 14.961 respondentes, encontraram associação entre a extroversão, considerado um traço de personalidade universal, e a propensão ao boca a boca. Além disso, pessoas em culturas caracterizadas por altos níveis de extroversão são mais propensas a utilizar e confiar em fontes de informação interpessoal do que pessoas que vivem em ambientes culturais 
em que o traço de extroversão não é tão saliente. Em outro estudo sobre a relação dos traços de personalidade e o boca a boca, Marquis e Filiatrault (2002) verificaram que o boca a boca negativo foi mais frequente em indivíduos mais reservados, ao passo que esse comportamento parece ser utilizado para diminuir os efeitos da insatisfação. Além disso, Marquis e Filiatrault (2002) também encontraram que os altos níveis de consciência conduzem a um boca a boca negativo mais intenso.

Ainda na relação entre traços de personalidade e boca a boca, Ferguson, Paulin e Bergeron (2010) encontraram que os traços de amabilidade e extroversão podem ter uma relação significativa com o boca a boca positivo. No mesmo sentido, Hoye e Lievens (2009) evidenciaram uma relação significativa entre a extroversão e o boca a boca positivo, complementando que o traço de consciência também pode anteceder esse comportamento. Hoye e Lievens (2009) ainda mostraram que o traço de consciência pode anteceder o boca a boca negativo.

Na junção com a personalidade, Mowen, Park e Zablah (2007) dividiram o construto de boca a boca em dois construtos secundários, sendo o primeiro relativo ao envio de informações e o segundo, relacionado com o recebimento de informações do mercado, procurando, por meio de traços de personalidade, predizer níveis de propensão individual para o envio e recebimento dessas informações.

Nesse sentido, Mowen, Park e Zablah (2007) buscaram relações da personalidade, por meio do Modelo $3 \mathrm{M}$, preconizado por Mowen (2000), com o envio e recebimento de informações do mercado, como facetas do boca a boca. Ressalta-se que, entre os traços elementares utilizados naquele estudo, estão os traços dos cinco fatores, que serão usados neste estudo. Tal como naquele estudo, as relações serão feitas de modo a explorar quais características de personalidade possuem maior impacto nas disposições para o envio e recebimento de informação do mercado.

Baseadas nos indicativos acerca da relação entre os traços de personalidade e as disposições de envio e recebimento de informações, são apresentadas as seguintes hipóteses de estudo:

$\mathrm{H}_{1}$ : Os traços de personalidade de (a) neurotismo, (b) introversão, (c) amabilidade, (d) consciência e (e) abertura à experiência apresentarão um impacto significativo na disposição ao envio de informação.

$\mathrm{H} 2$ : Os traços de personalidade de (a) neurotismo, (b) introversão, (c) amabilidade, (d) consciência e (e) abertura à experiência apresentarão um impacto significativo na disposição ao recebimento de informação.

Com base no exposto, o modelo teórico de estudo é proposto graficamente na Figura 1, sendo todos os traços de personalidade propostos pelo modelo dos cinco fatores relacionados a ambas as facetas utilizadas do boca a boca, uma vez que este estudo procura ligações entre a personalidade e a disposição para a expressão de comportamentos boca a boca.

\section{Figura 1. Modelo do estudo}

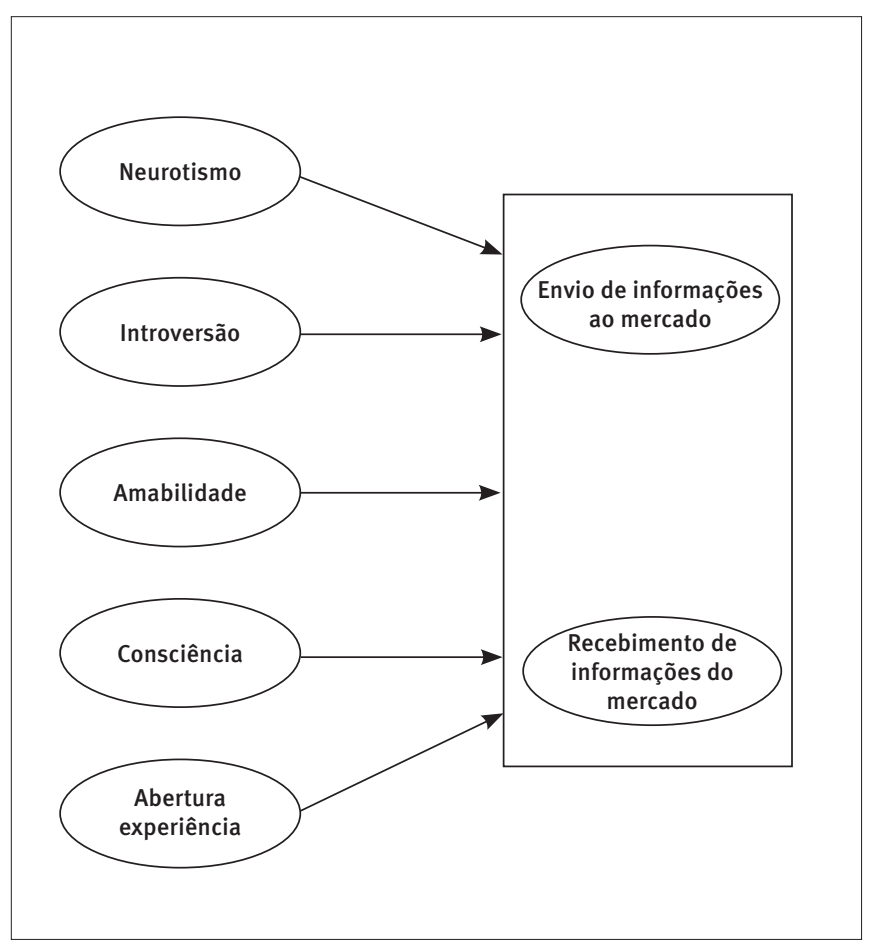

\section{MÉTODO}

Para operacionalização deste estudo, a população estudada foi composta por estudantes de graduação em Administração de uma instituição de ensino superior do estado do Rio Grande do Sul. A amostra de 283 estudantes foi feita por conveniência dos pesquisadores, selecionando os entrevistados que estavam em sala de aula durante a semana de coleta dos dados. Esse tamanho amostral foi considerado adequado, segundo as proposições de Hair e outros (1998), para a utilização de modelagem de equações estruturais, em que se deve ter ao menos cinco observações para cada variável independente. Ressalta-se que este estudo caracteriza-se por ser uma pesquisa descritiva de corte transversal.

Todas as escalas utilizadas nesta pesquisa foram convertidas da língua inglesa para a portuguesa e, após, sofreram o processo de tradução reversa, para a identificação de possíveis dissonâncias na primeira tradução. As escalas adotadas foram do tipo Likert de 11 pontos, tendo uma variação entre o e 10.

Para os traços de personalidade (amabilidade, instabilidade emocional, introversão, consciência e abertura à experiência), foram utilizadas as mesmas escalas propostas por 
Mowen (2000). Já para os construtos de envio e recebimento de informação do mercado, relativos ao boca a boca, as escalas foram retiradas de Mowen, Park e Zablah (2007).

A pesquisa foi operacionalizada por um questionário, aplicado em sala de aula. Os alunos foram avisados de que as respostas eram anônimas, e a entrega dos instrumentos preenchidos foi feita após a finalização do preenchimento por todos os presentes. Esses procedimentos foram empregados para reduzir a probabilidade de que as respostas dos indivíduos fossem direcionadas por aspectos sociais (respostas socialmente desejáveis).

Para o teste do instrumento, foi realizado um pré-teste, com a coleta de 30 casos por meio de entrevista pessoal, em sala de aula, com a presença dos pesquisadores. Nesse pré-teste, não foram identificados problemas quanto ao entendimento das escalas utilizadas e quanto ao processo de preenchimento do instrumento de coleta de dados.

Após coletados, os dados foram tratados no software SPSS $®$. Para tanto, foi analisada a qualidade do banco de dados; os missing values, que foram substituídos pela média em cada variável, não sendo encontrados valores maiores que $5 \%$ em missing values para cada variável; os outliers foram identificados por estatísticas uni (teste z) e multivariadas (distância $D^{2}$ de Mahalanobis), e, após, retirados da análise; nisso, foram retirados seis casos; a normalidade dos dados foi comprovada por meio de cálculos de assimetria e curtose, enquanto a multicolinearidade foi verificada por meio de cálculos de correlação bivariada e pelo cálculo de tolerância, não sendo encontrado nenhum caso; por fim, a homocedasticidade dos dados das variáveis incluídas no modelo de equações estruturais foi verificada por meio do teste de Levene (HAIR e outros, 1998), com os grupos formados pelas variáveis gênero e renda.

\section{RESULTADOS}

A análise dos dados será dividida entre a caracterização da amostra; a verificação da qualidade dos construtos utilizados; e os resultados decorrentes da análise por meio de modelagem de equações estruturais, feita com o software Lisrel v.8.51, com o método de estimação de verossimilhança.

\section{Caracterização da amostra}

$\mathrm{Na}$ amostra, 52,7\% dos respondentes são homens, com idade média de 26,4 anos e renda média entre $R \$ 1.500,00$ e $R \$$ 3.000,00. Também foram utilizadas as variáveis de personalidade para a caracterização dos respondentes, em que a Tabela 1 apresenta as médias em cada dimensão, distinguindo entre indivíduos do gênero masculino e feminino.

\section{TABELA 1. Traços de personalidade dos entrevistados pelo sexo}

\begin{tabular}{|c|c|c|c|c|}
\hline \multirow{2}{*}{ Dimensões da personalidade } & \multicolumn{2}{|c|}{ Masculino } & \multicolumn{2}{|c|}{ Feminino } \\
\hline & Média & Desvio-Padrão & Média & Desvio-Padrão \\
\hline Amabilidade & $7,70^{*}$ & 1,67 & $8,00^{*}$ & 1,24 \\
\hline Instabilidade emocional & 4,83 & 1,78 & 4,85 & 1,78 \\
\hline Introversão & 4,74 & 1,77 & 4,49 & 1,94 \\
\hline Consciência & 6,97 & 1,57 & 6,82 & 1,52 \\
\hline \multirow[t]{2}{*}{ Abertura à experiência } & 6,91 & 1,40 & 7,01 & 1,28 \\
\hline & \multicolumn{2}{|c|}{$N=146$} & \multicolumn{2}{|c|}{$\mathrm{N}=131$} \\
\hline
\end{tabular}

Nota: ${ }^{\star} p \leq 0,05$.

Com base nos resultados da Tabela 1, foi possível identificar que os traços de personalidade não apresentam manifestações diferentes de acordo com o gênero (com exceção do traço de amabilidade, que foi mais presente em mulheres do que em homens).

\section{Avaliação dos construtos}

Para avaliar a confiabilidade e a validade dos construtos, uma análise fatorial confirmatória foi feita, com o método de estima- ção por verossimilhança. Nessa análise, em que as covariâncias entre os construtos foram estimadas, os índices mostram um ajuste adequado do modelo fatorial $\left(x^{2}=694,71 ; g l=384 ; p<0,01\right.$; $\mathrm{GFI}=0,86 ; \mathrm{RMSEA}=0,05 ; \mathrm{NNFI}=0,91 ; \mathrm{CFI}=0,92 ; \mathrm{IFI}=0,92)$.

A qualidade das escalas foi verificada por meio da confiabilidade de construto e da variância extraída, apresentados na Tabela 2. Convém destacar que, segundo Hair e outros (1998), índices adequados de confiabilidade de construto devem figurar acima de 0,70, enquanto índices adequados de variância extraída devem ser superiores a 0,50. 


\section{TABELA 2. Confiabilidade dos construtos}

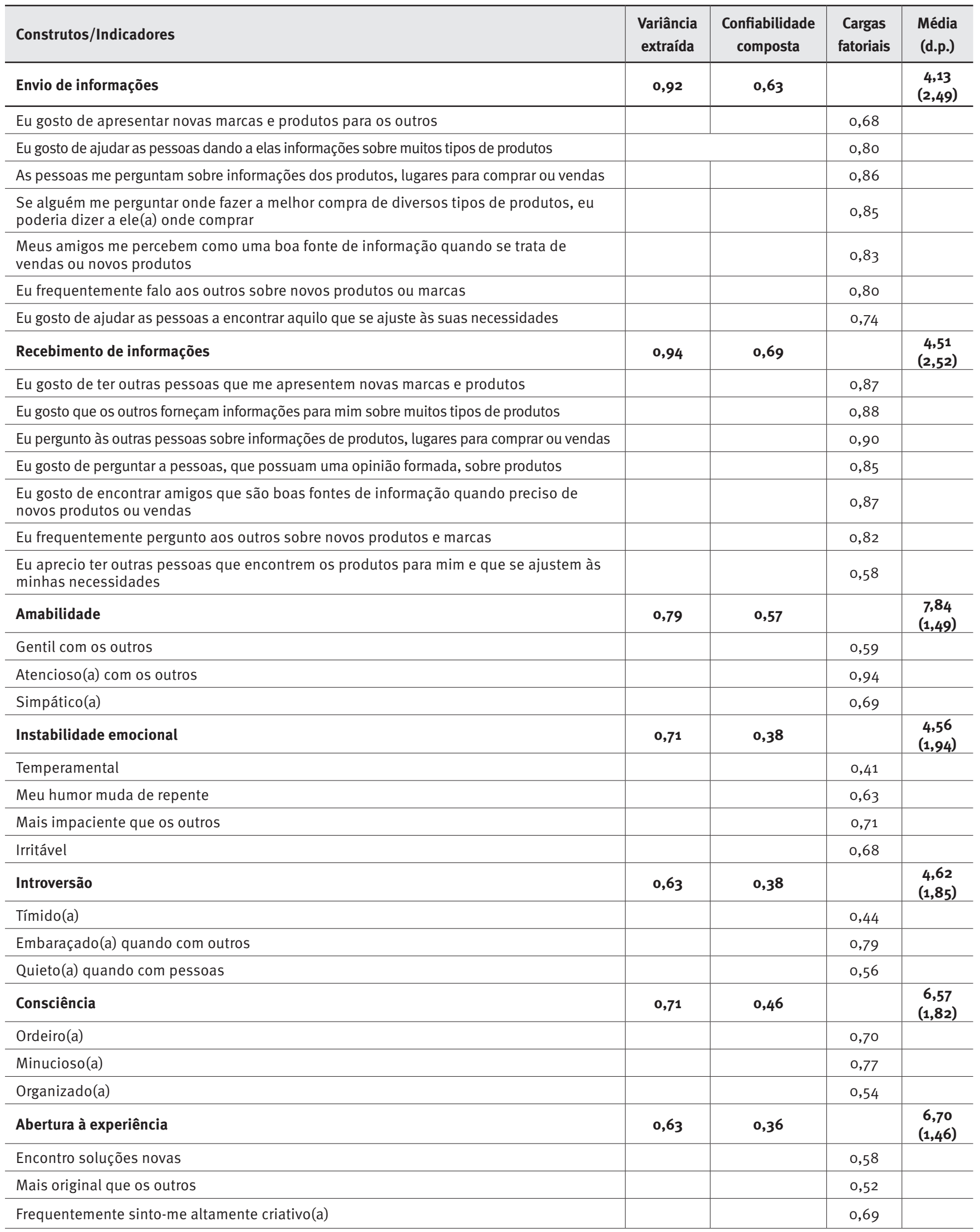


Verifica-se que alguns construtos tiveram índices de confiabilidade abaixo do ideal. A introversão e a abertura à experiência foram os construtos que tiveram índices de confiabilidade e/ou variância extraída abaixo do desejável, todavia constata-se que resultados semelhantes também foram obtidos em outros estudos que utilizaram as mesmas escalas (MONTEIRO e VEIGA, 2006). Nesse sentido, e corroborando as afirmativas de Mowen (2000), as escalas desenvolvidas para mensurar tais traços de personalidade podem ser objeto de estudos futuros, que, por sua vez, podem tanto verificar suas propriedades psicométricas quanto os aspectos concernentes à validade dos construtos a que se referem.
Sequencialmente, a validade convergente e discriminante foi avaliada. A validade convergente foi verificada por meio da significância dos valores de $t$ em cada construto. Dessa forma, todos os indicadores apresentaram valores de $t$ superiores a 1,96, não sendo encontrados casos que pudessem provocar a rejeição da validade convergente dos construtos.

Já a validade discriminante foi avaliada segundo a técnica descrita por Fornell e Larcker (1981), em que as variâncias compartilhadas são comparadas com as variâncias extraídas (quadrado da correlação entre os construtos). Com base nas correlações entre os construtos evidenciadas na Tabela 3, essa validade pode ser verificada.

\section{TABELA 3. Correlação entre os construtos}

\begin{tabular}{|c|c|c|c|c|c|c|c|}
\hline Construto & 1 & 2 & 3 & 4 & 5 & 6 & 7 \\
\hline 1. Envio de informações & 1,00 & & & & & & \\
\hline 2. Recebimento de informações & 0,76 & 1,00 & & & & & \\
\hline 3. Amabilidade & 0,10 & 0,04 & 1,00 & & & & \\
\hline 4. Instabilidade emocional & 0,20 & 0,31 & $-0,27$ & 1,00 & & & \\
\hline 5. Introversão & 0,05 & 0,18 & $-0,13$ & 0,66 & 1,00 & & \\
\hline 6. Consciência & 0,28 & 0,17 & 0,13 & 0,07 & 0,11 & 1,00 & \\
\hline 7. Abertura à experiência & 0,01 & 0,13 & $-0,07$ & 0,08 & 0,02 & $-0,11$ & 1,00 \\
\hline
\end{tabular}

Os pressupostos da validade discriminante não foram aceitos para a instabilidade emocional, que apresentou uma variância compartilhada $(43,6 \%)$ com a introversão que supera a sua variância extraída (38\%). Para tanto, optou-se, no modelo, pela correção dessa alta correlação encontrada entre os dois construtos e também sugerida pelo alto índice de modificação encontrado $(54,800)$. Ressalta-se que essa correção foi feita para a reespecificação e melhoramento do ajuste do modelo, e embasa-se também na suposição de McCrae e Costa (1987) de que os traços de personalidade podem coexistir e ser correlacionados. Heffernan e outros (2008) também mencionam que os traços de personalidade que compõem o modelo Big Five (utilizados neste estudo) possuem baixo poder discriminante.

A alta correlação encontrada entre o envio e o recebimento de informações, apesar de não representar inferências contrárias à validade discriminante, retrata a ligação entre esses dois construtos, que, segundo Mowen, Park e Zablah (2007), representam duas faces do boca a boca.
Seguindo as orientações de Garver e Mentzer (1999), a unidimensionalidade dos construtos presentes no modelo foi verificada pela observação de um número relativamente baixo de resíduos padronizados, identificados por meio da AFC. Dessa forma, nenhum caso de resíduo padronizado maior que $\pm 2,58$ foi encontrado, confirmando a unidimensionalidade dos construtos.

\section{Modelagem de equações estruturais}

A modelagem de equações estruturais (MEE) foi escolhida como técnica de análise dos dados. 0 procedimento de estimação utilizado foi o de estimação de máxima verossimilhança, na matriz de covariância utilizada.

Dessa forma, a Tabela 4 apresenta os resultados dos caminhos estruturais, evidenciando os coeficientes padronizados $(\beta)$, os respectivos valores de $t$, bem como os coeficientes de explicação dos construtos dependentes do modelo. Além disso, são apresentados os índices de ajuste do modelo utilizado. 
TABELA 4. Resultados da modelagem de equações estruturais

\begin{tabular}{|c|c|c|c|c|}
\hline Caminhos estruturais & $\beta$ & $\mathbf{t}$ & $\mathbf{R}^{\mathbf{2}}$ & Índices de ajuste \\
\hline Introversão … Envio de informações & $-0,19$ & $-1,56$ & \multirow[t]{2}{*}{0,15} & $p<0,001$ \\
\hline Consciência $\cdot \cdots \cdot$ Envio de informações & $0,26^{\star \star}$ & 3,28 & & $x^{2} / g l: 1,58$ \\
\hline Amabilidade $\cdot . .$. Recebimento de informações & 0,12 & 1,78 & \multirow[b]{3}{*}{0,16} & RMSEA: 0,04 \\
\hline Instabilidade emocional ..... Recebimento de informações & $0,37^{\star *}$ & 2,77 & & NNFI: 0,93 \\
\hline Introversão -... Recebimento de informações & $-0,07$ & $-0,58$ & & CFI: 0,94 \\
\hline Correlação: Instabilidade emocional - Introversão & $0,66^{\star \star}$ & 3,95 & & \\
\hline
\end{tabular}

Nota: ${ }^{*} \mathrm{p} \leq 0,05 ;{ }^{* *} \mathrm{p} \leq 0,01$

O modelo possui um ajuste adequado, em face dos índices apresentados (HAIR e outros, 1998). Em virtude da aceitação do modelo, os caminhos estruturais têm sua análise apresentada na sequência.

O envio de informações foi significativamente antecedido pela amabilidade, instabilidade emocional e consciência. A amabilidade, ao relacionar-se positivamente com o envio de informações, pode indicar que pessoas que possuem preocupação e atenção com outros indivíduos têm uma maior disposição interna a enviar comunicações boca a boca. Da mesma forma, indivíduos mais organizados e pragmáticos, como indica a consciência, tendem a propagar informações. Já em termos absolutos, a instabilidade emocional foi o construto antecedente do envio de informações com maior coeficiente padronizado, indicando que as variações de humor e de temperamento podem fazer com que o indivíduo possua uma maior propensão ao envio de informações a terceiros. A não significância da introversão parece ocorrer devido à retração social que indivíduos com altos níveis desse traço enfrentam (MCCRAE e COSTA, 1997), uma vez que, para enviar informações, é necessária a interação com outras pessoas, atividade inibida pela introversão. Da mesma forma, a abertura à experiência não apresentou uma relação significativa com o envio de informações, podendo ser consequência da não percepção de excitação no envio de informações pela amostra estudada, uma vez que a abertura à experiência refere-se à busca por novas e excitantes atividades.

0 recebimento de informações, por sua vez, foi significativamente precedido pela instabilidade emocional e pela consciência, indicando que os indivíduos mais propensos a ou- vir comunicações boca a boca são aqueles mais instáveis emocionalmente, isto é, com propensões temperamentais e que também possuem um senso mais elevado de organização e pragmatismo. A amabilidade não foi um antecedente significativo do recebimento, diferentemente do encontrado para o envio de informações, o que pode representar que indivíduos preocupados com os outros não possuem uma predisposição a receber a informação, apenas a enviá-la. No mesmo sentido, a introversão e a abertura à experiência não foram antecedentes significativos da propensão ao recebimento de informações, o que pode indicar que pessoas tímidas e/ou que buscam ações ou eventos diferentes não possuem tendência a ouvir as comunicações boca a boca de outros indivíduos.

Para atestar a validade do modelo proposto, dois modelos alternativos ou rivais foram testados. Primeiro, os traços de personalidade foram tratados como antecedentes diretos apenas do envio de informações, sendo essa faceta tratada como antecedente do recebimento de informações. Os resultados desse modelo indicam uma piora nos ajustes $\left(x^{2}=623,84\right.$; $\mathrm{gl}=389 ; p<0,01)$, uma vez que a variação do qui-quadrado em relação ao modelo proposto foi significativa $\left(\Delta x^{2}=13,49\right.$; $p<0,05)$, e os indicadores de ajuste foram menores que aqueles evidenciados na Tabela 4 ( $\mathrm{GFI}=0,86$; $\mathrm{RMSEA}=0,05 ; \mathrm{NNFI}=0,93$; $\mathrm{CFI}=0,93 ; \mathrm{IFI}=0,93)$. 0 mesmo comportamento ocorre quando o recebimento de informações é consequente direto dos traços de personalidade e antecedente do envio de informações, que, por sua vez, é impactado apenas pelo recebimento de informações. Nesse segundo modelo, os resultados também indicam uma piora nos indicadores de ajuste do modelo (GFI=0,86; RM- 
$\mathrm{SEA}=0,05 ; \mathrm{NNFI}=0,93 ; \mathrm{CFl}=0,93 ; \mid \mathrm{Fl}=0,93)$, que foi significativa, conforme indica a diferença de qui-quadrado encontrada $\left(\Delta x^{2}=11,76 ; p<0,05\right)$. Nesse sentido, os resultados, além de evidenciarem que o modelo proposto se ajusta melhor aos dados e provê melhores efeitos, também fornecem um indicativo de que ambas as disposições internas, envio e recebimento de informações, podem estar fortemente correlacionadas, não havendo ordem de ocorrência. Esses resultados corroboram os achados e afirmações de Mowen (2000) acerca da correlação entre as disposições internas do indivíduo, ou seja, uma disposição específica (envio de informação, neste caso) relativa a uma disposição comportamental mais ampla (boca a boca, neste caso) pode apresentar uma forte correlação com outra disposição específica (recebimento de informação, neste caso) que se encontre sob o domínio de uma disposição mais ampla.

\section{DISCUSSÕES E IMPLICAÇÕES}

Por meio das análises apresentadas no estudo, foi possível verificar a aceitação do seu pressuposto, ou seja, conforme sugerem Mowen, Park e Zablah (2007), variáveis de personalidade, por representarem disposições internas do indivíduo, podem estar relacionadas com expressão de comportamentos póscompra, e neste caso, com o comportamento de boca a boca.

A relação significativa e positiva encontrada entre a amabilidade e o envio de informações pode representar a necessidade que os indivíduos possuem de compartilhar experiências para garantir suas interações sociais e também para prevenir que outros indivíduos passem por situações semelhantes, caso estas sejam negativas (BUSS, 1991). No mesmo sentido, McCrae e Costa (1987) afirmam que esse traço leva o indivíduo a fazer julgamentos morais a respeito de suas ações, podendo transmitir os resultados a outros, tal como acontece em uma interação de comunicação boca a boca.

No mesmo sentido, a instabilidade emocional, como antecedente do envio de informações, pode representar as disposições que os indivíduos possuem quando apresentam atividade temperamental ou, até mesmo, quando não possuem uma constância em seu humor, o que, de acordo com Campbell (1999), pode ser desencadeado quando o consumidor percebe uma situação de injustiça na qual é desfavorecido, passando, então, a sentir emoções negativas, que podem provocar o envio de informações ao mercado. Em uma justificativa psicológica, Buss (1991) afirma que a personalidade do indivíduo é moldada em suas interações com o meio, e, quando este percebe uma ameaça, um mecanismo de defesa é ativado, fazendo com que procure se defender, sendo uma das formas de defesa, nesse caso, a externalização dos sentimentos, para que as emoções entrem novamente em equilíbrio. Ainda com relação aos antecedentes do envio de informações, a consciência indica que indivíduos com senso de organização e eficiência para execução das tarefas são mais propensos a enviar informações.

Por sua vez, a propensão a receber informações foi significativamente precedida pela instabilidade emocional, indicando que indivíduos temperamentais possuem não só a propensão a enviar informações como também a de recebê-las. No que tange ao envio, os indivíduos podem estar fazendo uso desse tipo de comunicação para procurar restabelecer a estabilidade de suas emoções, quando em desequilíbrio, ou seja, o boca a boca pode agir como um mecanismo de defesa e satisfação psicológica para esses indivíduos. Em relação à propensão a receber informações, ela pode revelar uma maneira de esses indivíduos se prevenirem contra situações que possam lhes trazer prejuízos (CAMPBELL, 1999). No mesmo sentido, o recebimento de informações também pode estar relacionado à eliminação ou supressão de dúvidas e incertezas sobre compras e consumo. Essas explicações para a relação entre a instabilidade emocional e a propensão a receber informações podem ser objeto de estudos futuros.

Por fim, a relação positiva encontrada entre a consciência e o recebimento de informações pode indicar que indivíduos com características de organização e de objetividade em suas tarefas possuem uma maior propensão a receber informações. McCrae e Costa (1987) citam que indivíduos com maiores níveis desse traço de personalidade são planejadores e direcionados à execução das tarefas, sendo mais cuidadosos e disciplinados, o que pode estar ligado à obtenção de informações, uma vez que estas podem auxiliar o indivíduo na execução disciplinada e cuidadosa de suas tarefas.

\section{CONSIDERAÇÕES FINAIS}

Primeiramente, esta pesquisa evidenciou que é possível relacionar construtos psicológicos, como a personalidade, com construtos da área de marketing, sob uma perspectiva de previsão de comportamentos dos consumidores, partindo do pressuposto, citado por Baumgartner (2002), de que novos métodos de estudo devem ser utilizados. Também foi possível evidenciar diversas disposições ou traços individuais (MOWEN, 2000) que podem ser responsáveis por desencadear comportamentos de pós-compra (CHEUNG, ANITSAL, ANITSAL, 2007).

Os traços de amabilidade, instabilidade emocional e consciência podem estar ligados diretamente à expressão de 
comportamentos de boca a boca, evidenciando que as disposições individuais podem representar um meio preditivo para a identificação desses comportamentos.

0 estudo da personalidade aplicado ao marketing pode trazer impactos no conhecimento mais profundo do consumidor e, consequentemente, uma orientação mais focada da empresa em seus consumidores. Outro aspecto que pode ser inferido pela personalidade no contexto de marketing é a possibilidade de desenvolvimento de comunicações mais objetivas e que possuam maior influência sobre os consumidores, uma vez que a identificação das redes motivacionais dos traços associados aos comportamentos pode gerar informações sobre quais meios de comunicação sejam mais eficientes para o alcance e, também, qual conteúdo a mensagem deve conter, a fim de ser assertiva aos resultados esperados perante os consumidores. Os achados desta pesquisa indicam que os temas de mensagens podem ser desenvolvidos com base nos traços de personalidade e, assim, pode-se prever ou antever quais serão os efeitos daquela comunicação, isto é, se a mensagem tenderá a instigar os traços de personalidade e, dessa forma, desencadear os comportamentos de boca a boca esperados pela organização.

Em outro raciocínio, a compreensão de quais traços de personalidade inferem na propensão ao envio e recebimento de informações do mercado pode ser importante para que a organização consiga prevenir expressões de boca a boca negativo, que podem ser consequência de percepções de injustiça (CAMPBELL, 1999). Por isso, gerencialmente, considera-se que a organização deve atentar para as características de seus consumidores, para evitar comunicações indesejáveis e potencializar as desejáveis, que podem trazer benefícios.

Este estudo limita-se pela utilização de disposições internas do indivíduo, podendo estudos futuros incluir medidas comportamentais, para realmente analisar a ligação entre as disposições individuais e o comportamento de boca a boca. Além disso, sugere-se que essa avaliação seja feita em diferentes situações e locais, obtendo, assim, medidas mais precisas dos relacionamentos diretos que existem entre os traços e as variáveis de boca a boca.

A população utilizada neste estudo foi de acadêmicos, o que, a priori, representa um grupo homogêneo e pode interferir nos resultados, pois algumas características podem ser compartilhadas entre os indivíduos, por frequentarem o mesmo local (faculdade) e consumirem regularmente o mesmo serviço (educação), estando sob tipos de influências semelhantes. Assim, sugere-se a realização de estudos futuros em ambientes mercadológicos puros, onde as populações possam ter heterogeneidade maior e não compartilhem das mesmas experiências com frequência. Essa sugestão implica também uma maior variabilidade de traços de personalidade.

Novos estudos podem abranger a estrutura do Modelo 3M, preconizado por Mowen (2000), por meio do qual uma estrutura hierárquica de personalidade é utilizada para predição de comportamentos dos indivíduos. Aliado a isso, novos estudos também podem verificar a influência da cultura (BENET-MARTINÉZ e JOHN, 1998) na relação entre os traços de personalidade e a disposição ao envio/recebimento de informações.

\section{REFERÊNCIAS}

BANSAL, H. S; VOYER, P. A. Word-of-mouth processes within a services purchase decision context. Journal of Service Research, v. 3, n. 2, p. 166170,2000

BAUMGARTNER, H. J. Toward a personology of the customer. Journal of Consumer Research, v. 29, n. 2, p. 286-292, 2002.

BEARDEN, W. O; NETEMEYER, R. G; TEEL, J. E. Measurement of consumer susceptibility to interpersonal influence. Journal of Consumer Research, v. 15 , n. 4 , p. $473-481,1989$.

BENET-MARTÍNEZ, V; JOHN, O. P. Los cinco grandes across cultures and ethnic groups: multitrait multimethod analyses of the big five in Spanish and English. Journal of Personality and Social Psychology, v. 75, n. 3, p. 729-750, 1998.

BODEY, K; GRACE, D. Segmenting service "complainers" and "noncomplainers" on the basis of consumer characteristics. Journal of Services Marketing, v. 20, n. 3, p. 178-187, 2006.

BOVE, L; MITZIFIRIS, B. Personality traits and the process of store loyalty in a transactional prone context. Journal of Services Marketing, v. 21, n. 7, p. 507-519, 2007.

BUSS, D. M. Evolutionary personality psychology. Annual Review Psychology, v. 42, p. 459-491, 1991.

CAMPBELL, M. C. Perceptions of price unfairness: antecedents and consequences. Journal of Marketing Research, v. 36, n. 2, p. 187-199, 1999.

CHEUNG, M. S; ANITSAL, M. M; ANITSAL, I. Revisiting word-of-mouth communications: a cross-national exploration. Journal of Marketing Theory and Practice, v. 15, n. 3, p. 235-249, 2007.

DUAN, W; GU, B; WHINSTON, A. B. The dynamics of online world-ofmouth and product sales: an empirical investigation of the movie industry. Journal of Retailing, v. 84, n. 2, p. 233-242, 2008.

FERGUSON, R. J; PAULIN, M; BERGERON, J. Costumer sociability and the total service experience: antecedents of positive word-of-mouth intentions. Journal of Service Management, v. 21, n.1, p. 25-44, 2010.

FORNELL, C; LARCKER, D. F. Structural equation models with unobservable variables and measurement error: algebra and statistics. Journal of Marketing Research, v. 18, n. 3, p. 382-388, 1981.

GARVER, M. S; MENTZER, J. T. Logistics research methods: employing structural equation modeling to test for construct validity. Journal of Business Logistics, v. 20, n. 1, p. 33-57, 1999.

GAZZANIGA, M; HEATHERTON, T. Ciência psicológica: mente, cérebro e comportamento. 2. ed. São Paulo: Artmed, 2005. 
GOLDBERG, L. R. The structure of phenotypic personality traits. American Psychologist, v. 48, n. 1, p. 26-34, 1993.

HAIR, J. F; ANDERSON, R. E; TATHAM, R. L; BLACK, W. C. Multivariate data analysis. Upper Saddle River: Prentice-Hall, 1998.

HARRIS, E. G; MOWEN, J. C. The influence of cardinal-, central-, and surface-level personality traits on consumers' bargaining and complaint intentions. Psychology \& Marketing, v. 18, n. 11, p. 1155-1185, 2001.

HEFFERNAN, T; O’NEILL, G; TRAVAGLIONE, T; DROULERS, M. Relationship marketing: the impact of emotional intelligence and trust on bank performance. International Journal of Bank Marketing, v. 26, n. 3, p. 183199, 2008.

HORTON, R. L. Some relationships between personality and consumer decision making. Journal of Marketing Research, v. 16, n. 2, p. 233-246, 1979.

HOYE, G. V; LIEVENS, F. Tapping the grapevine: a closer look at word-ofmouth as a recruitment source. Journal of Applied Psychology, v. 94, n. 2, p. 341-352, 2009.

HURLEY, R. F. Customer service behavior in retail settings: a study of the effect of service provider personality. Journal of the Academy of Marketing Science, v. 26, n. 2, p. 115-127, 1998.

JAAKKOLA, E. Purchase decision-making within professional consumer services: organizational or consumer buying behaviour? Marketing Theory, v. 7, n. 1, p. 93-108, 2007.

JANSSENS, W; PELSMACKER, P. Smells like me: personality and perfume choice. International Journal of Market Research, v. 51, n. 4, p. 465-480, 2009.

KEMPF, D. S; PALAN, K. M. The effects of gender and argument strength on the processing of word-of-mouth communication. Journal of the Academy of Marketing Studies, v. 10, n. 1, p. 1-18, 2006.

LIBAI, B; BOLTON, R; BÜGEL, M. S; RUYTER, K; GÖTZ, O; RISSELADA, $\mathrm{H}$; STEPHEN, A. T. Customer-to-customer interactions: broadening the scope of word of mouth research. Journal of Service Research, v. 13, n. 3, p. 267-282, 2010.

Marquis, M; Filiatrault, P. Understanding complaining responses through consumers' self-consciousness disposition. Psychology \& Marketing, v. 19 , n. 3, p. 267-292, 2002

MATOS, C. A; ROSSI, C. A. V. Word-of-mouth communications in marketing: a meta-analytic review of the antecedents and moderators. Journal of the Academy of Marketing Science, v. 36, n. 4, p. 578-596, 2008.

MAZZAROL, T; SWEENEY, J. C; SOUTAR, G. N. Conceptualizing word-ofmouth activity, triggers and conditions: an exploratory study. European Journal of Marketing, v. 41, n. 11-12, p. 1475-1494, 2007.

MCCRAE, R. R; COSTA, P. T. Personality trait structure as a human universal. American Psychologist, v. 52, n. 5, p. 509-516, 1997.

MCCRAE, R. R; COSTA, P. T. Validation of the five-factor model of personality across instruments and observers. Journal of Personality and Social Psychology, v. 52, n. 1, p. 81-90, 1987.

MCKINSEY QUATERLY. A new way to measure word-of-mouth marketing April 2010. Disponível em: https://www.mckinseyquarterly.com/A_new_ way_to_measure_word-of-mouth_marketing_2567. Acesso em 29.07.2012.

MITTAL, B. An integrated framework for relating diverse consumer characteristics to supermarket coupon redemption. Journal of Marketing Research, v. 31, n. 4, p. 533-544, 1994.

MONTEIRO, P. R. R; VEIGA, R. T. Personalidade e consumo: uma avaliação empírica do modelo metateórico de motivação e personalidade. In: ENCONTRO NACIONAL DA ASSOCIAÇÃO NACIONAL OS PROGRAMAS DE PÓS-GRADUAÇÃO EM ADMINISTRAÇÃO, 30, 2006, Salvador. Anais. Rio de Janeiro: ANPAD, 2006.
MONTEIRO, P. R. R; VEIGA, R. T. Personalidade e segmentação do mercado de moda: contrastes e perfil de jovens inovadores segundo 0 gênero. Revista Pretexto, v. 10, n. 1, p. 69-87, 2009.

MONTEIRO, P. R. R; VEIGA, R. T; GONÇALVES, C. A. Previsão de comportamentos de consumo usando a personalidade. RAE-eletrônica, v. 8, n. 2, 2009. Disponivel em: http://rae.fgv.br/sites/rae.fgv.br/ files/artigos/10.1590_S1676-56482009000200008.pdf. Acesso em 29.07.2012.

MOORADIAN, T. A; OLVER, J. M. "I can't get no satisfaction": the impact of personality and emotion on postpurchase processes. Psychology \& Marketing, v. 14, n. 4, p. 379-393, 1997.

MOORADIAN, T. A; SWAN, K. S. Personality-and-culture: the case of a national extraversion and word-of-mouth. Journal of Business Research, v. 59, n. 6, p. $778-785,2006$.

MOWEN, J. C. The 3M model of motivation and personality: theory and empirical applications to consumer behavior. Boston: Kluer Academic Publishers, 2000.

MOWEN J. C; CARLSON, B. Exploring the antecedents and consumer behavior consequences of the trait of superstition. Psychology \& Marketing, v. 20, n. 12, p. 1045-1065, 2003.

MOWEN, J. C; PARK, S; ZABLAH, A. Toward a theory of motivation and personality with application to word-of-mouth communications. Journal of Business Research, v. 60, n. 6, p. 590-596, 2007.

MULYANEGARA, R. D; TSARENKO, Y; ANDERSON, A. The big five and brand personality: investigating the impact of consumer personality on preferences towards particular brand personality. Journal of Brand Management, v. 16, n. 4, p. 234-247, 2009.

NIELSEN. Global consumers' trust in 'earned' advertising grows in importance - April 2012. Disponivel em: http://www.nielsen.com/ us/en/insights/press-room/2012/nielsen-global-consumers-trust-inearned-advertising-grows.html. Acesso em 29.07.2012.

PIESKE, A. E; PRADO, P. H. M. Participação do consumidor no desenvolvimento do sistema Linux: aplicação do 3M de Mowen. Revista de Administração Faces Journal, v. 11, n. 1, p. 109-128, 2012.

PRICE, L. L; FEICK, L. F; HIGIE, R. A. Preference heterogeneity and coorientation as determinants of perceived informational influence. Journal of Business Research, v. 19, n. 3, p. 227-242, 1989.

RANAWEERA, C; PRABHU, J. On the relative importance of customer satisfaction and trust as determinants of customer retention and positive word of mouth. Journal of Targeting, Measurement and Analysis for Marketing, v. 12, n. 1, p. 82-90, 2003.

SCHMITT, D. P; REALO, A; VORACEK, M; ALLIK, J. Why can't a man be more like a woman? Sex differences in big five personality traits across 55 cultures. Journal of Personality and Social Psychology, v. 94, n. 1, p. 168-182, 2008.

SINGH, J. A. Typology of consumer dissatisfaction response styles. Journal of Retailing, v. 66, n. 1, p. 57-99, 1990.

WEITEN, W. Introdução à psicologia: temas e variações. 4. ed. São Paulo: Thomson Learning, 2006.

ZEITHAML, V. A; BERRY, L. L; PARASURAMAN, A. The behavioral consequences of service quality. Journal of Marketing, v. 6o, n. 2, p. 31-46, 1996.

ZHU, F; ZHANG, X. Impact of online consumer reviews on sales: the moderating role of product and consumer characteristics. Journal of Marketing, v. 74, n. 2, p. 133-148, 2010. 